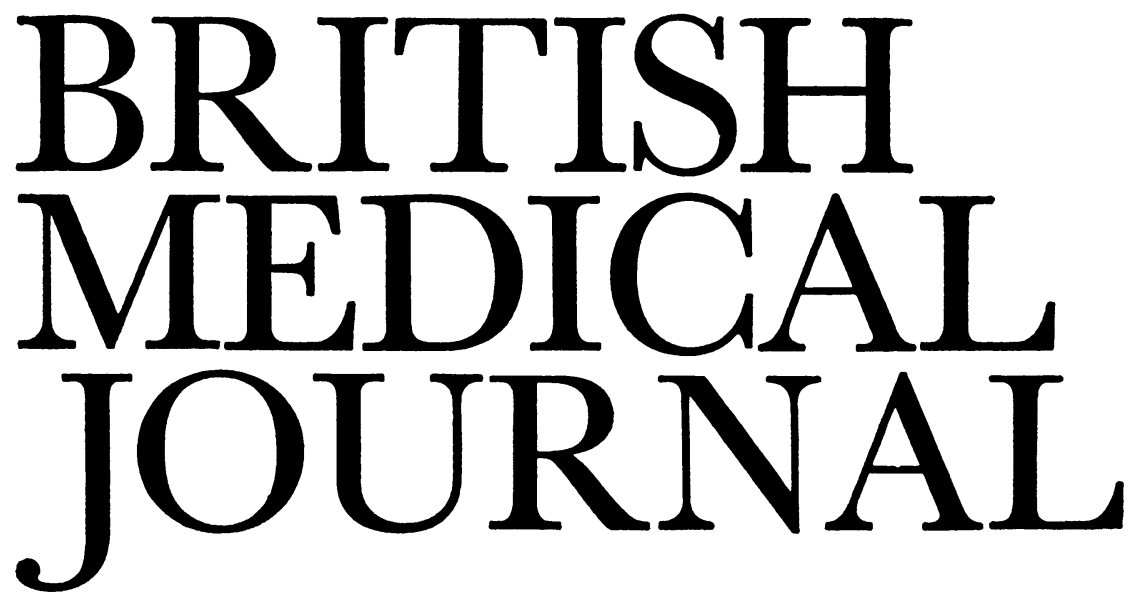

LONDON SATURDAY 13 MAY 1972

\title{
New Knees for Old
}

Operations to treat the arthritic knee may be divided into three groups: on soft tissues, on bones, and the arthroplasties. The only soft-tissue operation is synovectomy. It can benefit a chronically swollen, painful rheumatoid knee that has not responded to thorough medical treatment. Two operations on bones commonly performed are the high tibial osteotomy popularized by $\mathbf{M}$. Coventry ${ }^{1}$ and A. Benjamin's double osteotomy, ${ }^{2}$ wherein both the lower end of the femur and upper end of the tibia are cut. These operations are of greatest benefit in the treatment of an osteoarthritic knee accompanied by valgus or varus deformities. Also within this group comes arthrodesis, applicable to both rheumatoid and osteoarthritic knees. It is the only operation which, if successful, gives complete relief of pain, but since the result is total loss of function of the knee joint its applications are limited.

In an arthroplasty of any joint the aim is to relieve symptoms and maintain or restore function to the joint. The first attempt at an arthroplasty was performed by J. B. Murphy in America in 1913 using fat and fascia as a lining for the joint. ${ }^{3}$ In 1940 W. C. Campbell ${ }^{4}$ reported on the use of vitallium plates as a covering for the femoral condyles. Two cases were operated on; both failed. William N. Jones, of the Massachusetts General Hospital, revived the possibility of covering the femoral condyles with a vitallium cap and in 1971 reported good or very good results in 50\% of rheumatoid knees. ${ }^{5}$

D. L. MacKintosh ${ }^{6}$ and D. C. McKeever both concentrated on replacing one or both tibial plateaux with implants, initially of plastic but subsequently of chrome-cobalt alloy. These operations were used in the treatment of both rheumatoid and osteoarthritic knees, and MacKintosh in 1971 reported $69 \%$ success rate with his prosthesis. T. A. Potter, M. S. Weinfeld, and W. H. Thomas, ${ }^{7}$ using the McKeever prosthesis, obtained good or excellent results in $56 \%$ of rheumatoid knees and in nearly $85 \%$ of osteoarthritic knees. Such excellent results are not always reported, and L. G. P. Shiers, ${ }^{8} 9$ reviewing the world literature on knee arthroplasty in 1960, found a success rate of $42.7 \%$ in a total of 831 cases.

In the past 15 years attempts have been made to produce an entirely artificial knee joint. Interest in it has revived owing to the dramatic results of total hip replacement.
The problems associated with the design of a knee joint are very different from those encountered in the hip. In the hip the prime essential is for a satisfactory joint. Limiting factors need not be built in to restrain the range of movement, and, being a ball and socket joint, it is inherently stable. In the knee joint provision must be made to limit extension, and the artificial joint, if of a hinge variety, must replace the action of the sacrificed collateral and cruciate ligaments.

But the human knee is not a simple hinge, for as it flexes and extends the tibia glides backwards and forwards on the overlying femur. Yet a third movement also occurs - a rotation of the tibia on the femur. Several varieties of hinge joint are available, and $\mathrm{B}$. Waldius ${ }^{10}$ has reported a success rate of $84 \%$ in the treatment of rheumatoid knees, a figure that compares favourably with those for total hip replacement. For replacement operation on the knee patients have to be selected with greater precision than for hip surgery. For example, it is permissible to insert a total hip replacement in a monarticular arthritic, but it might be unwise to do so in respect of the knee joint. An artificial knee joint of the hinge variety oversimplifies the type of movement that normally occurs at the knee and has also to stabilize the knee against valgus and varus strains and against anterior and posterior strains applied to the tibia in relation to the femur. Consequently it is all the better for having the strains on it lessened by a reduction in the patient's activity. For this reason an artificial knee joint is apt to be more helpful to a rheumatoid patient, owing to his reduced activity, than to an osteoarthritic.

The faults inherent in a simple hinge joint have led to the independent development by F. H. Gunston, ${ }^{11}$ of Winnipeg, and $M$. Freeman, ${ }^{12}$ of London and the Royal National Orthopaedic Hospital, of a new concept in the surgery of total knee replacement. Their artificial joints comprise "runners" which are attached to the femoral condyles and which articulate in "tracks" inserted into the tibial condyles. These are so designed as to allow the normal hinging, gliding, and rotating to occur in the artificial joint. The combonents are inserted in such a manner as to take up slack in the patient's collateral ligaments, thus restoring lateral stability. The cruciate ligaments are not sacrificed and the absence of an anterior cruciate ligament, 
so often found in the rheumatoid knee, does not appear to be a contraindication to a successful arthroplasty of knee joint. ${ }^{13}$

At present, therefore, arthroplasty of the knee must be viewed with caution. No operation in any field of surgery carries certainty of success, and in the event of failure some salvage procedure must be available. After a failed total hinge replacement, especially if cement (methylmethacrylate) has been used to anchor the component parts of the joint within the femoral and tibial shafts, it can be exceedingly difficult, and sometimes impossible, to obtain an arthrodesis, which is the only salvage procedure available after a failed arthroplasty. In this event amputation is inevitable. The role of the artificial knee joint is thus somewhat limited, and the operation is best confined to patients with rheumatoid arthritis whose activities will be curtailed by disease of other joints in the lower limbs.

1 Coventry, M., Fournal of Bone and Foint Surgery, 1965, 47A, 984.

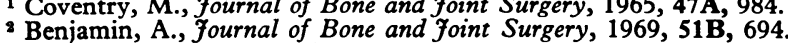

Benjamin, A., Fournal of Bone and foint Surgery,

3 Murphy, J. B., Annals of Surgery, 1913, 57, 593.

Jones, W. N., in Surgery of Rheumatoid Arthritis. International Symposium on Surgery in Rheumatoid Arthritis, May 1970 in Montreal, ed. R. L. Cruess and N. S. Mitchell, p. 35. Philadelphia, J. B. Lippincott, 1970 .

- MacKintosh, D. L., in Surgery of Rheumatoid Arthritis. International Symposium on Surgery in Rheumatoid Arthritis, May 1970 in Montreal, ed. R. L. Cruess and N. S. Mitchell, p. 29. Philadelphia, J. B. Lippincott, 1970.

7 Potter, T. A., Weinfeld, M. S., and Thomas, W. H., Fournal of Bone and foint Surgery, 1972, 54-A, i.

${ }^{3}$ Shiers, L. G. P., Fournal of Bone and Foint Surgery, 1960, 42B, 31.

Shiers, L. G. P., Rheumatism, 1961, 17, 54

10 Waldius, B., in Surgery of Rheumatoid Arthritis. International Symposium on Surgery in Rheumatoid Arthritis, May 1970 in Montreal, ed. R. L. on Surgery in Rheumatoid Arthritis, May 1970 in Montreal, ed. R. L.
Cruess and N. S. Mitchell, p. 47. Philadelphia, J. B. Lippincott, 1970. Cruess and N. S. Mitchell, p. 47. Philadelphia, J. B. Lippincott,
11 Gunston, F. H., fournal of Bone and foint Surgery, 1971, 53B, 272 .

12 Freeman, M., and Swanson, S. A. V., Fournal of Bone and foint Surgery, $1972,54 B, 170$.

13 Potter, T. A., Weinfeld, M. S., and Thomas, W. H., fournal of Bone and foint Surgery, 1972, 54A, 1.

\section{Incest and Family Disorder}

Despite reports by A. C. Kinsey and colleagues ${ }^{1}$ and the evidence of clinical experience, incest has generally been considered rare. Now $\mathrm{N}$. Lukianowicz ${ }^{2}$ in a comprehensive study from County Antrim reports a prevalence of $4 \%$ for paternal incest among unselected female psychiatric patients, and among 700 psychiatric patients of both sexes $29(4 \%)$ had some experience of other forms of incest. Among these 29 people the incest was between brother and sister in 15 cases, one grandfather and five of his granddaughters, uncle and niece in four cases, mother and son in three, and the two remaining relationships were between aunt and nephew.

Paternal incest was initiated by fathers between the age of 30 and 40 years when their daughters were aged between 5 and 14 years. The relationship continued on average for eight years, usually starting with the eldest girl but often later involving younger siblings. They were usually members of large working-class families living in cramped quarters in industrial towns or living in extreme isolation in rural areas. The fathers were habitually unemployed, often themselves from broken homes, and had usually left home after little schooling to work sporadically as labourers. Of 26 fathers studied all were of average intelligence, none was psychotic, but 14 were diagnosed as inadequate psychopaths, 5 as aggressive psychopaths, and 4 as alcoholics. As reported by other authors, ${ }^{3}$ many of these men appeared to be highly sexed, engaging in regular intercourse with the victim, her siblings, mother, and sometimes a mistress as well.

The mothers were on the whole dejected, felt overburdened by their large families, and had a husband who was described as habitually unemployed, inefficient, "good for nothing," or an aggressive, demanding bully. Eight of the mothers were promiscuous and showed psychopathic traits, two were frigid, three were excessively anxious, one had died, and twelve were regarded as without gross personality deviation. They usually colluded with the husband in his behaviour or chose to deny its existence.

Of the 26 daughters, 11 became promiscuous and had psychopathic traits such as drug abuse or delinquency; five girls developed frigidity after marriage, and three of these gave other evidence of hysterical personality disorder. Four girls developed frank psychiatric symptoms. In one this was an acute anxiety neurosis clearly precipitated by her father's continual threats of violence if she disclosed their clandestine relationship, and three girls developed depressive reactions with repeated suicide attempts. Only six girls $(23 \%)$ showed no apparent ill effects from their incestuous relationship.

As to other types of incest, the initiating partner was the woman in the three cases of mother-son and the two of aunt-nephew incest. All three of the mothers had a psychiatric abnormality. One was schizophrenic, another markedly neurotic, and the third later developed an involutional depression. One of the sons was schizophrenic, the next mentally subnormal, and the third left home after two years of incestuous relationships. One of the two aunts was clearly hypomanic and the other elated and sexually promiscuous. Psychiatric abnormality did not figure prominently in the other relationships, and 27 of the 30 partners involved in brother-sister incest were free from personality disorder, neurosis, and psychosis. Lukianowicz concludes that none of the participants in incest with partners other than father showed any serious ill effects and the majority of them showed no effect at all. Of those involved in paternal incest the high prevalence of disordered behaviour confirms the view expressed by other authors ${ }^{4}$ that the victims of incest develop character disorders rather than psychosis or neurosis, but in the presence of such gross family pathology it is not possible to isolate the incest as the cause of these abnormalities.

The offspring of incestuous unions have a greater morbidity and mortality than the average ${ }^{56}$ and it seems likely that this accounts for the existence of the incest taboo in almost every known society. The strong emotion aroused by violation of the taboo suggests the existence of a set of general tendencies that need to be denied. Elaborate taboos designed to inhibit a particular behaviour do not develop in the absence of widespread impulses towards the expression of the prohibited act. Freud 7 accorded the satisfactory resolution of the conflicts aroused by incestuous wishes a central place in personality development but recognized that the prohibition is really culturally determined. Some daughters are provocative and fathers provoked, but incest occurs only when the normal constraints of the family or of society break down. This breakdown cannot be traced to a single source. The fathers are often oversexed, undercontrolled, and underoccupied. The mothers are overwhelmed and at times delegate the maternal role to their daughters, who may be willing to accept it. Indeed it has been argued that the incestuous relationship often holds together an otherwise disintegrating family. ${ }^{8}$ These families 